\title{
Evaluasi Orally Disintegrating Tablet (Odt) Famotidin Variasi Superdisintegrant Starch 1500 Dan Crospovidone
}

\author{
Evaluation Orally Disintegrating Tablet (Odt) Famotidin Variation Of Superdisintegrant Starch 1500 \\ And Crospovidone
}

Siti Susilowati dan Nur Aini Dewi Purnamasari*

Fakultas Farmasi, Universitas Setia Budi, Surakarta

*Corresponding author: aldensaud@gmail.com, dp.nuraini@,gmail.com

\begin{abstract}
ABSTRAK
Famotidin digunakan sebagai obat tukak duodenum dan tukak lambung, sehingga cocok dibuat sediaan Orally Disintegrating Tablet (ODT). ODT memiliki karakteristik yang cepat terdisintegrasi di dalam rongga mulut. Penelitian ini bertujuan untuk mengetahui apakah famotidin dapat dibuat sediaan ODT, pengaruh superdisintegrant starch 1500 dan crospovidone terhadap mutu fisik sediaan, dan konsentrasi superdisintegrant starch 1500 dan crospovidone sehingga diperoleh ODT famotidin dengan waktu hancur yang cepat.

Penelitian ini memformulasikan ODT famotidin dengan superdisintegrant starch 1500 7\%, kombinasi superdisintegrant starch 1500 dan crospovidone 3\%:4\%, dan menggunakan superdisintegrant crospovidone 7\%. Pembuatan ODT famotidin menggunakan metode kempa langsung. Pengujian yang dilakukan untuk mengetahui mutu fisik ODT famotidin adalah keseragaman bobot, ukuran, kekerasan, kerapuhan, waktu pembasahan, waktu hancur, keragaman kandungan, uji tanggap rasa, uji waktu hancur in vivo kemudian hasil dianalis menggunakan uji statistik SPSS Statistics versi 23.

Hasil yang diperoleh menunjukkan bahwa famotidin dapat dibuat sediaan ODT, superdisintegrant starch 1500 dan crospovidone berpengaruh terhadap mutu fisik sediaan dan kombinasi superdisintegrant starch 1500 dan crospovidone 3\%:4\% menghasilkan waktu hancur cepat yaitu 34,30 detik.
\end{abstract}

Kata kunci : Orally Disintegrating Tablet, Famotidine, Starch 1500 dan Crospovidone

\section{ABSTRACT}

Famotidine is used as a duodenal and gastric ulcers, making it suitable for Orally Disintegrating Tablets (ODT) preparations. ODT has characteristics that quickly dissociate in the oral cavity. The objective of this study was to investigate is that famotidine can be made ODT preparations, the effect of superdisintegrant starch 1500 and crospovidone on the physical quality of preparations, and concentration of superdisintegrant starch 1500 and crospovidone to obtain famotidine ODT with rapid destruction time.

This study formulated ODT famotidine with a superdisintegrant starch $15007 \%$, combination of superdisintegrant starch 1500 and crospovidone $3 \%: 4 \%$, and using a superdisintegrant crospovidone $7 \%$. Preparation of famotidine ODT using direct induced method. Tests conducted to determine the physical quality of famotidine ODT are uniformity of weight, size, hardness, brittleness, wetting time, crushed time, diversity of content, taste test, crushed test time in vivo and then analyzed using statistical test SPSS Statistics version 23.

The results showed that famotidine can be made ODT preparations, superdisintegrant starch 1500 and crospovidone have an effect on the physical quality of preparations, and combination of superdisintegrant starch 1500 and crospovidone $3 \%: 4 \%$ resulted in rapid destruction time of 34.30 seconds.

Keywords: Orally Disintegrating Tablet, Famotidine, Starch 1500 dan Crospovidone

\section{PENDAHULUAN}

Ulkus peptikum merupakan suatu keadaan terputusnya kontinuitas mukosa yang meluas di bawah epitel atau kerusakan pada jaringan mukosa, submukosa hingga lapisan otot dari suatu daerah saluran cerna yang langsung berhubungan dengan cairan lambung asam/pepsin (Sanusi,
2008). Gejala yang khas yaitu nyeri ulu hati yang kadang- kadang menjalar ke pinggang disertai mual dan muntah (Tarigan, 2006). Salah satu pengobatan yang digunakan adalah famotidin. Famotidin merupakan obat Ulkus peptikum golongan antagonis reseptor $\mathrm{H} 2$ yang dapat menghambat sekresi asam lambung 
dengan cara berkompetensi dengan histamin untuk berikatan dengan reseptor $\mathrm{H} 2$ pada parietal lambung, bila histamin berikatan dengan reseptor $\mathrm{H} 2$ maka akan dihasilkan asam, dengan di blokirnya tempat ikatan antara histamin dan reseptor digantikan dengan obatobat ini maka asam tidak akan dihasilkan (Berardy \& Lynda, 2005). Famotidin yang beredar dipasaran umumnya berbentuk tablet, namun karena sediaan tersebut dinilai kurang praktis dan efisien dalam penggunaanya maka dibuat sediaan tablet Orally Disintegrating Tablet (ODT).

ODT merupakan tablet yang mengandung bahan aktif yang larut atau hancur di rongga mulut tanpa pelarut air atau mengunyah (Gupta et al., 2010). ODT sebagai suatu bentuk sediaan padat yang mengandung bahan obat atau bahan aktif yang terdisintegrasi dengan cepat biasanya dalam hitungan detik ketika ditempatkan pada lidah, sehingga bentuk sediaan ODT diharapkan memberikan manfaat bagi penderita ulkus peptikum karena obat ini didesain untuk dapat hancur dengan cepat yaitu kurang dari 1 menit dengan atau tanpa bantuan air. Untuk mempercepat proses hancurnya tablet maka diperlukan bahan superdisintegran.

Superdisintegran yang digunakan dalam penelitian ini adalah starch 1500 dan crospovidone. Starch 1500 merupakan superdisintegran dengan mekanisme pengembangan (swelling). Superdisintegran dengan mekanisme swelling memiliki waktu hancur lebih lama dibandingkan dengan superdisintegran dengan mekanisme kapiler (wicking), sehingga bahan penghancur ini dikombinasikan dengan crospovidone. Crospovidone bekerja dengan kombinasi mekanisme yaitu kapiler (wicking), pengembangan (swelling) dan perubahan bentuk (deformation) (Santanu et.al., 2012). Kombinasi kedua superdisintegran diharapkan $O D T$ famotidin dapat hancur cepat kurang dari 1 menit. Starch 1500 biasa digunakan sebagai superdisintegran pada konsentrasi 5-10\%
(Rowe et.al., 2009), sedangkan crospovidone digunakan sebagai superdisintegran pada konsentrasi 1-10\%.

Berdasarkan hal tersebut dilakukan pembuatan $O D T$ famotidin dengan kombinasi superdisintegran starch 1500 dan crospovidone secara kempa langsung. Penelitian ini bertujuan untuk mengetahui apakah famotidin dapat dibuat ODT dan mengetahui pengaruh penggunaan superdisintegran terhadap mutu fisik ODT famotidine serta konsentrasi superdisintegrant starch 1500 dan crospovidone sehingga diperoleh ODT famotidin dengan waktu hancur yang cepat.

\section{METODE PENELITIAN}

\section{Alat dan bahan}

Alat yang digunakan dalam penelitian ini yaitu timbangan analitik (Alsep EX-200 A), mortir, stamfer, batang pengaduk, stopwatch, pipet volume, labu takar, mesin tablet single punch, corong kaca besar, jangka sorong, klem dan statif, friability tester (Eweka Gmb-H tipe TA), hardness tester, (Stokes skala 1-15 kg), beaker glass, cawan petri, Spektrofotometer UV-Vis (UV-1800).

Bahan dalam penelitian ini yaitu famotidin, avicel pH 102, aspartam, starch 1500, crospovidone, $\mathrm{Mg}$. stearat, talk, aquadest, metilen blue, larutan dapar fosfat pH 2,5, larutan dapar fosfat $\mathrm{pH} 6,8$.

\section{Jalannya Penelitian}

1. Pembuatan larutan induk. Pembuatan larutan induk famotidin dengan cara menimbang 15,1 mg famotidin kemudian dilarutkan dengan larutan dapar fosfat $0,02 \mathrm{M}, \mathrm{pH} 2,5$ sampai $500 \mathrm{ml}$, sehingga diperoleh larutan induk dengan kadar 30,2 ppm. Sebanyak $5 \mathrm{ml}$ larutan diambil \& diencerkan sampai $10 \mathrm{ml}$ dengan Larutan dapar fosfat 0,02 M, pH 2,5, sehingga diperoleh larutan induk dengan kadar $15,1 \mathrm{ppm}$. 


\section{Penentuan panjang gelombang maksi-} mum. Larutan induk famotidin dengan kadar 15,1 ppm dibaca absorbansinya pada panjang gelombang 240-300 nm, sehingga diperoleh panjang gelombang maksimal.

3. Pembuatan kurva baku famotidin. Larutan induk famotidin diencerkan hingga diperoleh berbagai konsentrasi 9,06; 12,08; 15,$1 ; 18,2 ; 21,14 ; 24,16$ ppm. Seri larutan tersebut diukur serapannya dengan pektrofotometer UV-Vis pada panjang gelombang maksimum famotidin.

4. Pembuatan ODT famotidin. ODT famotidin dibuat sebanyak 3 formula yang berbeda kandungan superdisintegran. Formula ODT dapat di lihat pada Tabel 1.

ODT famotidin dibuat dengan metode kempa langsung, dengan berbagai kombinasi bahan. Menimbang semua bahan yang diperlukan sesuai dengan formulasi yang sudah ditentukan. Langkah berikutnya yaitu mencampurkan bahan famotidin, starch 1500 dan crospovidone, avicel PH 102 dan aspartam pada masing-masing formula I, II, dan III, aduk sampai homogen. Masing-masing dari formula ditambahkan talk, Mg Stearat dan dicampur hingga homogen. Campuran tersebut kemudian dicetak dengan mesin tablet single punch. Tablet dicetak dengan bobot rata-rata $200 \mathrm{mg}$.

\section{Pengujian Mutu Fisik}

\section{A. Mutu fisik granul}

1). Waktu alir granul. Sejumlah 100 gram serbuk dimasukkan dalam corong yang ujung tangkainya sudah ditutup terlebih dahulu. Pada saat melepas tutup ujung corong, secara bersamaan tekan stopwatch dan dimatikan setelah semua granul keluar dari corong. Waktu yang diperlukan untuk mengalirnya jika 100 gram serbuk yang diuji mempunyai waktu alir kurang dari 10 detik atau mempunyai waktu alir minimal 10 gram per detik (Sulaiman, 2007).

2). Sudut diam. Sudut diam dilakukan dengan menimbang 100 gram serbuk dimasukkan kedalam alat pengujian yang berupa corong yang ditutup pada lubang keluarnya. Granul akan mengalir bebas dari sebuah corong ke dasar membentuk suatu kerucut (Voigt, 1994).

\section{B. Mutu fisik ODT famotidin}

1). Uji keseragaman bobot ODT. Sebanyak 20 tablet dibersihkan dari debu kemudian ditimbang satu persatu, dihitung bobot rata ratanya dan standar deviasinya. Pengujian keseragaman bobot ditentukan berdasarkan pada besar dan kecilnya penyimpangan bobot tablet yang dihasilkan dibandingkan dengan rata-rata tablet (Anief, 2004).

2). Uji keseragaman kandungan ODT.

Tabel 1. Formula ODT famotidin

\begin{tabular}{lccc}
\hline \multirow{2}{*}{ Nama bahan } & \multicolumn{3}{c}{ Formula $(\mathrm{mg})$} \\
\cline { 2 - 4 } & F1 & F2 & F3 \\
\hline Famotidin & 20 & 20 & 20 \\
Starch 1500 & 14 & 6 & - \\
Crospovidone & - & 8 & 14 \\
Avicel pH 102 & 161 & 161 & 161 \\
Talk & 1 & 1 & 1 \\
Mg Stearat & 2 & 2 & 2 \\
Aspartam & 2 & 2 & 2 \\
\hline Berat Total & 200 & 200 & 200 \\
\hline
\end{tabular}

Keterangan : F1 : starch 1500 7\% (14 mg), F2 : starch $15003 \%$ ( $6 \mathrm{mg}$ ) dan crospovidone 4\% (8 mg), F3 : crospovidone $7 \%$ (14 mg). 
Diambil secara acak sejumlah 20 ODT famotidin kemudian digerus sampai halus. Serbuk ditimbang dengan seksama $200 \mathrm{mg}$ (setara dengan $20 \mathrm{mg}$ famotidin), dimasukkan kedalam labu takar $50 \mathrm{~mL}$, \& ditambahkan sedikit demi sedikit larutan dapar fosfat $\mathrm{pH} 6,8$ sambil dikocok sampai homogen, tambahkan larutan dapar fosfat $\mathrm{pH}$ 6,8 sampai tanda batas kemudian disonifikasi selama 20 menit.Setelah disonifikasi larutan disaring dengan menggunakan kertas saring, ambil $2 \mathrm{ml}$ larutan dimasukkan dalam labu takar $50 \mathrm{~mL}$ kemudian tambahkan larutan dapar fosfat $\mathrm{pH}$ 6,8 sampai tanda batas. Pembacaan absorbansi sampel dilakukan secara spektrofotometri UV-Vis (Raju et al., 2009).

3). Uji kekerasan ODT. Mengambil 10 tablet dari masing-masing formula. Satu persatu tablet diletakkan ditengah dan tegak lurus pada hardness tester, mula-mula skala pada posisi nol, kemudian dengan alat diputar pelan-pelan sampai tablet pecah. Dibaca skala yang dicapai pada saat tablet tepat pecah atau hancur. Tablet yang baik mempunyai kekerasan antara 3-6 kg.

4). Uji kerapuhan ODT. Dua puluh tablet dibebas debukan, ditimbang, dimasukkan ke dalam friabilator diputar selama 4 menit dengan kecepatan 25 putaran per menit. Tablet dibersihkan dari fines yang menempel dan ditimbang kembali. Batas tertinggi kerapuhan tablet yang dapat diterima adalah 0,8\% sampai 1\% (Lachman et al.,1994).

\section{5). Uji waktu disintegrasi ODT. Tablet} diletakkan diatas cawan petri yang memiliki diameter $6,5 \mathrm{~cm}$ yang berisi $6 \mathrm{~mL}$ larutan dapar fosfat $\mathrm{pH}$ 6,8. Hitung waktu dari awal tablet dimasukkan ke dalam cawan petri sampai tablet dapat disintegrasi seluruhnya menjadi partikelpartikel halus, kemudian catat waktunya sebagai waktu disintegrasi tablet.
6). Uji waktu pembasahan ODT. Waktu pembasahan tablet diukur menggunakan prosedur sederhana. Kertas saring diletakkan dicawan petri, kemudian dengan larutan metilen blue dan $6 \mathrm{~mL}$ larutan dapar fosfat $\mathrm{pH} 6,8$. Sebuah tablet diletakkan diatas permukaan kertas saring yang basah. Waktu yang diperlukan untuk air mencapai permukaan atas tablet dicatat sebagai waktu pembasahan (Parmar et al., 2009).

7). Uji waktu hancur in-vivo. Uji dilakukan dengan menggunakan 20 responden. Responden berkumur terlebih dahulu sebelum dilakukan pengujian tablet, kemudian tablet diletakkan diatas lidah, tidak boleh ditelan maupun dikunyah. Hancurnya tablet dapat diketahui dengan cara menghidupkan stopwatch pada saat tablet sudah dilidah sampai tablet hancur dilidah.

8). Analisa Hasil. Data uji mutu fisik yang diperoleh dari pengujian dibandingkan dengan persyaratan yang ada di dalam Farmakope Indonesia dan literatur lainnya (Widyaningrum, 2015), serta analisis statistik dengan SPSS versi 23.

\section{HASIL DAN PEMBAHASAN}

\section{A. Pembuatan kurva kalibrasi \& penetapan kadar}

1. Penentuan panjang gelombang serapan maksimum.

Penentuan panjang gelombang serapan maksimum dilakukan untuk mendapatkan serapan (absorbansi) paling baik. Dari larutan yang akan dianalisis dengan memperkecil interfensi senyawa-senyawa pengganggu. Panjang gelombang serapan maksimum yang didapat akan digunakan untuk penetapan kadar kandungan zat aktif dan banyaknya zat yang terdisolusi. Larutan induk dengan konsentrasi 15,1 ppm discanning pada panjang gelombang 
240-300 nm secara spektrofotometri UV-Vis. Hasil yang diperoleh pada penelitian ini adalah panjang gelombang $266 \mathrm{~nm}$ dengan absorbansi 0,4585 .

\section{Penentuan kurva baku}

Penentuan kurva baku famotidin menggunakan larutan induk famotidin dengan konsentrasi 9,06 ppm, 12,08 ppm, 15,1 ppm, 18,12 ppm, 21,14 ppm dan 4,16 ppm di dapat hasil absorbansi antara 0,2-0,8. Hasil absorbansi beberapa kurva kalibrasi dapat dilihat pada Gambar 1.

\section{B. Hasil Pemeriksaan Mutu Fisik Granul}

Pemeriksaan mutu fisik granul merupakan tahapan dalam pembuatan tablet untuk mengetahui sifat fisik granul, sehingga menjamin kualitas sediaan $O D T$ yang dihasilkan. Pemeriksaan mutu fisik granul meliputi waktu alir dan sudut diam. Hasil pemeriksaan mutu fisik granul sebagai berikut.

\section{Kecepatan alir}

Kecepatan alir merupakan parameter sifat alir yang dapat menyatakan granul tersebut memiliki sifat alir yang baik atau tidak. Pemeriksaan waktu alir berpengaruh terhadap homogenitas granul. Apabila formula sediaan ODT. mempunyai sifat alir yang baik, maka akan menghasilkan bobot $O D T$ yang seragam.
Semakin kecil harga waktu alir maka sifat alirnya akan semakin baik. Suatu serbuk dikatakan mempunyai waktu alir baik jika mempunyai waktu alir tidak lebih dari 10 detik/100 gram serbuk.

Hasil penelitian waktu alir serbuk dapat dilihat pada tabel 2 menunjukan bahwa massa tablet dari seluruh formula memiliki sifat alir yang baik, yang berarti massa tablet dapat mengalir dengan baik saat memasuki ruang cetak pada proses kompresi tablet sehingga akan diperoleh keseragaman dalam pengisian yang akan menjamin keseragaman sediaan.

\section{Sudut diam}

Hasil pemeriksaan sudut diam pada formula I $27,47^{\circ}$, formula II $28,51^{\circ}$, formula III $28,95^{\circ}$ Menunjukkan bahwa serbuk memenuhi persyaratan yang telah ditentukan yaitu granul pada formula I, II dan III mempunyai sudut diam kurang dari $30^{\circ}$ sehingga pada setiap formula mempunyai kecepatan alir yang baik.

\section{Hasil Pemeriksaan Mutu Fisik ODT}

Pemeriksaan mutu fisik $O D T$ merupakan indikator awal untuk mengetahui $O D T$ yang dibuat telah memenuhi persyaratan pustaka yang telah ada, sehingga diharapkan $O D T$ yang dihasilkan memiliki mutu fisik ODT yang baik, dan sesuai persyaratan yang ada. Hasil pemeriksaan mutu fisik ODT famotidine dapat dilihat pada Tabel 3 .

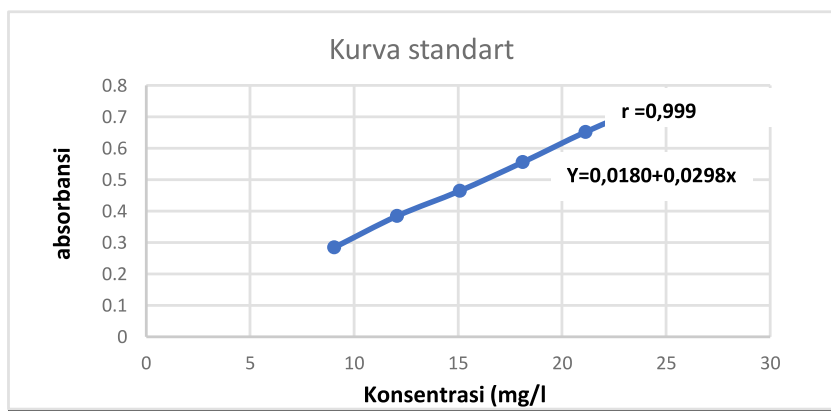

Gambar 1. Kurva baku famotidin

Tabel 2. Hasil pemeriksaan mutu fisik granul

\begin{tabular}{lccc}
\hline Parameter & F1 & F2 & F3 \\
\hline Kecepatan Alir (detik) & $1,63 \pm 0,030$ & $2,01 \pm 0,010$ & $2,86 \pm 0,020$ \\
\hline Sudut Diam $\left(^{\circ}\right)$ & $27,47 \pm 0,450$ & $28,51 \pm 0,257$ & $28,95 \pm 0,916$ \\
\hline
\end{tabular}


Tabel 3. Hasil pemeriksaan mutu fisik $O D T$ famotidin

\begin{tabular}{llll}
\hline Pemeriksaan & Formula 1 & Formula 2 & Formula 3 \\
\hline Keseragaman bobot (mg) & $206,75 \pm 4,141$ & $201,75 \pm 2,881$ & $201,10 \pm 3,226$ \\
Keseragaman kandungan & $95,20 \pm 0,572$ & $98,81 \pm 0,221$ & $98,21 \pm 0,000$ \\
Kekerasan & $5,86 \pm 0,126$ & $5,68 \pm 0,244$ & $5,56 \pm 0,414$ \\
Kerapuhan (\%) & $0,07 \pm 0,001$ & $0,05 \pm 0,000$ & $0,11 \pm 0,017$ \\
Waktu pembasahan (detik) & $29,69 \pm 2,963$ & $20,12 \pm 2,453$ & $18,45 \pm 0,452$ \\
Waktu disintegrasi (detik) & $43,92 \pm 0,493$ & $34,30 \pm 1,126$ & $85,43 \pm 10,944$ \\
Waktu hancur in-vivo (detik) & $54,73 \pm 2,325$ & $44,42 \pm 2,488$ & $72,21 \pm 8,398$ \\
\hline
\end{tabular}

Keterangan :
F1 = Formulasi dengan starch $15007 \%(14 \mathrm{mg})$
F2 = Formulasi dengan starch $15003 \%(6 \mathrm{mg})$ dan crospovidone $4 \%$ ( $8 \mathrm{mg})$
F3 = Formulasi dengan crospovidone $7 \%(14 \mathrm{mg})$

\section{Keseragaman bobot}

Keseragaman bobot tablet secara tidak langsung sebagai penentu homogenitas zat aktif maupun bahan tambahan yang terkandung dalam $O D T$ famotidin. Keseragaman bobot tablet dipengaruhi oleh sifat alir dari serbuk karena sifat alir yang baik mempengaruhi pengisian dalam ruang kompresi dengan volume yang konstan sehingga diperoleh tablet dengan bobot yang seragam. Apabila nilai CV kurang dari $5 \%$, tablet yang dihasilkan memenuhi keseragaman bobot yang baik. Keseragaman bobot tablet dilakukan dengan menimbang secara acak 20 tablet. Hasil dari ketiga formula memenuhi keseragaman bobot yang baik yaitu formula I $0,02 \%$, formula II $0,01 \%$, formula III $0,02 \%$.

\section{Keseragaman kandungan}

Penetapan keseragaman kandungan dilakukan dengan mengambil 20 tablet dan ditentukan kadar zat aktifnya, tablet famotidin mengandung famotidin $\mathrm{C}_{8} \mathrm{H}_{15} \mathrm{~N}_{7} \mathrm{O}_{2} \mathrm{~S}_{3}$ tidak kurang dari 90,0\% dan tidak lebih dari 110,0\% dari jumlah yang tertera pada etiket (Kemenkes RI, 2014). Dari hasil uji keseragaman kandungan yang dilakukan, menunjukkan bahwa ketiga formula memiliki kadar formula 1 $=95,20 \%$,dengan $\mathrm{SD}=0,57 \%$, formula $2=$ $98,81 \%$, dengan $\mathrm{SD}=0,22 \%$, formula $3=$
$98,21 \%$ dengan $\mathrm{SD}=0,00 \%$, sehingga ketiga formula masuk dalam persyaratan keseragaman kandungan yang ditetapkan.

\section{Kekerasan}

Berdasarkan hasil penelitian dapat diketahui bahwa kekerasan dari formula I memiliki kekerasan $5,86 \mathrm{~kg}$, formula II $5,68 \mathrm{~kg}$, formula III $5,56 \mathrm{~kg}$, dari ketiga formula dapat disimpulkan bahwa ODT famotidin tersebut memenuhi persyaratan yaitu 3-6 kg. Hasil penelitian ketiga formula memiliki kekerasan yang berbeda hal ini disebabkan karena pada saat pengempaan pengisian granul pada die berbeda-beda dan superdisintegran yang dipakai dapat mempengaruhi kekerasan tablet.

Hasil uji statistik dengan KolmogorovSmirnov untuk kekerasan tablet ODT famotidin dari ketiga formula diperoleh signifikasi $(\mathrm{p})=$ $0,004<0,05$ yang berarti data tidak terdistribusi normal, maka dilanjutkan dengan uji KruskalWallis Test. Hasil kesimpulan Kruskal-Wallis Test diperoleh signifikasi $(\mathrm{p})=0,225>0,05$, menunjukkan bahwa ketiga formula tidak mempunyai perbedaan yang bermakna yang berarti superdisintegrant starch 1500 dan crospovidone tidak memberikan pengaruh kekerasan yang bermakna pada pembuatan tablet ODT. 


\section{Kerapuhan}

Nilai kerapuhan yang rendah dipengaruhi oleh kompaktibilitas massa tablet, tekanan kompresi, dan efisiensi dari filler binder yang digunakan. Secara keseluruhan hasil uji kerapuhan menunjukkan bahwa kerapuhan tablet memenuhi persyaratan yaitu kurang dari $1 \%$.

Hasil uji statistik menggunakan Kolmogorov Smirnov diperoleh hasil signifikasi $(\mathrm{p})=$ $0,129>0,05$ yang berarti data terdistribusi normal, uji lavene statistic 0,007 < 0,05 maka dilanjutkan dengan uji Kruskal-Wallis Test. Hasil kesimpulan Kruskal-Wallis Test diperoleh signifikasi $(p)=0,023<0,05$, yang berarti dari ketiga formula terdapat perbedaan yang bermakna.

\section{Waktu pembasahan}

Waktu pembasahan digunakan untuk mengetahui seberapa cepat ODT menyerap air, dimana kecepatan penyerapan air akan mempengaruhi kemampuan dan kecepatan waktu hancur tablet (Pamar et al., 2009). Dari penelitian didapatkan hasil formula I 29,69 detik, formula II 20,12 detik formula III 18,45 detik.

Sifat hidrofilik dan mekanisme wicking agent yang dimiliki oleh crospovidone menyebabkan air lebih cepat berpenetrasi ke dalam sediaan sehingga menyebabkan tablet memiliki waktu pembasahan yang cepat, sedangkan formula yang menggunakan starch 1500 dalam jumlah besar sebagai bahan penghancur memiliki waktu yang lebih lama dalam pembasahannya karena bentuk dan struktur starch 1500 yang berpori dan mekanisme swelling yang dimilikinya menyebabkan air lebih lama berpenetrasi ke dalam sediaan kemudian baru keluar secara lamban dan mengembang. Kombinasi kedua superdisintegrant memberikan pembasahan yang lebih cepat daripada formula dengan superdisintegrant starch 1500 dalam jumlah besar.

\section{Waktu disintegrasi}

Hasil penelitian pada formula 1 yaitu 43,92 detik, formula II yaitu 34,30 detik, formula III yaitu 85,43 detik, menunjukkan bahwa formula 1 dan 2 memenuhi kriteria $O D T$ yaitu memiliki waktu disintegrasi kurang dari 60 detik, sedangkan formula 3 tidak memenuhi kriteria ODT karena waktu hancurnya lebih dari 60 detik. Waktu hancur tablet pada formula 3 dengan komposisi crospovidone yang tinggi ternyata memiliki waktu hancur yang paling panjang dibandingkan dengan formula yang lainnya. Sifat hidrofilik dan mekanisme wicking agent yang dimiliki oleh crospovidone menyebabkan air lebih cepat berpenetrasi ke dalam sediaan sehingga menyebabkan tablet memiliki waktu pembasahan yang cepat tetapi memiliki waktu hancur yang relative lama karena kecepatan hancur hanya terjadi di bagian luar saja, tablet bagian dalam cenderung mengalami proses penghancuran yang lebih lambat sehingga waktu hancur menjadi lebih lama.

Hasil uji statistik Kolmogorov-Smirnov untuk waktu hancur dari ketiga formula diperoleh signifikasi $(p)=0,006<0,05$ menunjukkan bahwa data tidak terdistribusi normal maka dilanjutkan dengan uji Kruskal-Wallis Test. Hasil uji Kruskal-Wallis diperoleh signifikasi $(p)=0,027<0,05$ yang berarti dari ketiga formula terdapat perbedaan yang bermakna.

\section{Waktu hancur in-vivo}

Hasil pemeriksaan waktu hancur in vivo dapat dilihat pada Tabel 3. pada formula 2 mempunyai waktu hancur yang yang baik yaitu 44,42 detik hal tersebut karena kombinasi kerja kedua superdisintegrant, starch 1500 dengan bentuknya yang berpori menyerap banyak air secara sempurna sampai kedalam mengembang dan pecah dari dalam dipercepat dengan sifat peng- 
hancuran luar yang cepat oleh crospovidone sehingga tablet pecah sempurna dengan lebih cepat.

Hasil uji statistik Kolmogorov-Smirnov untuk waktu hancur in vivo dari ketiga formula diperoleh signifikasi $(p)=0,000<0,05$ menunjukkan bahwa data tidak terdistribusi normal maka dilanjutkan dengan uji Kruskal-Wallis. Hasil uji Kruskal-Wallis diperoleh signifikasi (p) $=0,000<0,05$ yang berarti dari ketiga formula terdapat perbedaan yang bermakna.

\section{KESIMPULAN}

Berdasarkan hasil penelitian dapat disimpulkan bahwa :

1. Famotidin dapat dibuat sediaan $O D T$

2. Superdisintegrant Starch 1500 dan Crospovidone berpengaruh terhadap suatu mutu fisik pada sediaan $O D T$ famotidin. dengan kombinasi kedua superdisintegrant dapat menurunkan waktu pembasahan, waktu disintegrasi,serta meningkatkan kekerasan tablet, dan menurunkan kerapuhan tablet.

3. Konsentrasi kombinasi superdisintegrant starch 1500 3\% dan crospovidone 4\%, mampu memberikan waktu disintegrasi yang singkat pada sediaan $O D T$ famotidin.

\section{DAFTAR PUSTAKA}

Anief M. 2004. Prinsip-Prinsip dan Dasar Farmakologi. Yogyakarta. Gajah Mada University Press. Hlm 48.

Berardi, R. R., \& Welage, L. S. 2008. Peptic Ulcer Disease. In J. T. Dipiro, R. L. Tabert,G. C. Yee, G. R. Matzke, B. G. Wells, \& L. M. Posey (Eds.), Pharmacotheraphy A Pathopshyologic Approach (7th ed., 569-578). New York: Mc. Graw Hill.

Gupta, A.K., Mittal, A. and Jha, K.K., 2012, Fast Dissolving Tablet: A Review, The Pharma Innovation, 1 (1): 1-8.

Kemenkes RI. 2014. Farmakope Indonesia. Edisi V. Kementrian Kesehatan Republik Indonesia. Jakarta.

Lachman L, Lieberman HA, Kaning JL. 1994, Teori dan Praktek Farmasi Industri, diterjemahkan oleh Suyatmi, Jilid II. Jakarta: Universitas Indonesia Press. hlm 165-166.

Pamar RB, Baria AH, Tank HM \& Faldus D. 2009. Formulation and evaluation of domperidone fast disolving tablet. Int. $J$. Pharm Tech Resert, (1): 483-487.

Raju SR, Shanmuganathan S, Sekharan TR, Kumar SRS and Thirupathi AT.2009. Formulation and evaluation of mouth dissolving famotidine tablet. International Journal of ChemTech Research CODEN(USA) :IJCRGG(1):12511256.

Rowe RC, Sheskey PJ, Quinn ME. 2009. Handbook of Pharmaceutical Excipient 7 th Ed. London: Pharmaceutical Press. Hlm. 206-208.

Santanu R, Hussan SD, Pooja V, Devina S and Sonam S.2012. A Concise Review On Novel Aspects Of Superdisintegrants : A Review. International Research Journal of Pharmaceutical and Applied, 2(6) : 207-213.

Sanusi, I. A. 2011. Tukak Lambung. In A. A. Rani, M. S. K., \& A. F. Syam (Eds.), BukuAjar Gastroenterologi (328-345). Jakarta: Interna Publishing.

Sulaiman TNS. 2007. Teknologi \& Formulasi Sediaan Tablet, Pustaka Laboratorium Teknologi Farmasi, Fakultas Farmasi, Universitas Gajdah Mada, Yogyakarta.

Tarigan, P. 2006. Tukak Gaster. In A. W. Sudoyo, B. Setiyohadi, I. Alwi, M. S. K., \& S.Setiati (Eds.), Ilmu Penyakit Dalam Jilid I (IV, 338-341). Jakarta: FKUI.

Voigt R. 1995. Buku Pelajaran Teknoloogi Farmasi. Yogyakarta: Gajah Mada University press. Hamilton. halm 475-479.

Widyaningrum E. 2015. Formulasi Fast Disintegrating Tablet Famotidin menggunakan kombinasi Superdisintegrant acdisol dan sodium starch glycolate [Skripsi]. Surakarta: Fakultas Farmasi, Universitas Setia Budi. Surakarta. 